\title{
Studies on the Toxicity of Smoke Containing Hydrogen Chloride
}

\author{
G. E. HARTZELL, A. F. GRAND, and W. G. SWITZER \\ Department of Fire Technology \\ Southwest Research Institute \\ 6220 Culebra Road \\ San Antonio, Texas 78238, USA
}

\section{ABSTRACT}

Hydrogen chloride (HC1) is a relatively common component of fire effluents about which there has been much speculation and controversy. The studies reported here represent a continuation of efforts to clarify the role of $\mathrm{HCl}$ in combustion toxicology.

Studies with rodent exposures have shown that at low concentrations of $\mathrm{HCl}$, sensory irritation causes a decrease in respiratory minute volume, with somewhat slower loading of $\mathrm{CO}$ and a delay in toxicological effects. At much higher $\mathrm{HCl}$ concentrations, pulmanary irritant effects are observed leading to postexposure lethality. An empirical analysis of data for mixtures of $\mathrm{HCl}$ and $\mathrm{CO}$ suggests that exposure doses leading to lethality may be additive.

The lethal toxic potency $\left(L C_{50}\right)$ of PVC smoke may be Targely, but not entirely, accounted for by the $\mathrm{HCl}$ produced. However, PVC smoke exhibited a greater incidence of early postexposure deaths. The early deaths, which may be partially attributable to a combined effect of $c 0$ and $\mathrm{HCl}$, may also be linked to the pattern of respiratory penetration by the smoke.

\section{EXPERIMENTAL METHODS AND MATERIALS}

Exposure of Animats

Apparatus. The exposure apparatus used in these studies, illustrated in Figure 1, is similar in size and shape to that commonly used in the NBS smoke toxicity test [1]. However, it was modified to create a "flow-through" system. The air flow through the exposure chamber ranged from about $30 \mathrm{~L} / \mathrm{min}$ up to about $200 \mathrm{~L} / \mathrm{min}$. This wide range of air flows was due to modification of the exhaust system during the course of the program in order to provide greater flexibility and control in generating and maintaining specific gas atmospheres. The higher flow rates permitted more rapid equilibration of the test atmospheres and more stability in the atmosphere once established.

The animal restraints and isolation system, used to protect the animals from the test atmosphere until equilibrium was established, was the same as that used in a previous study [2]. 


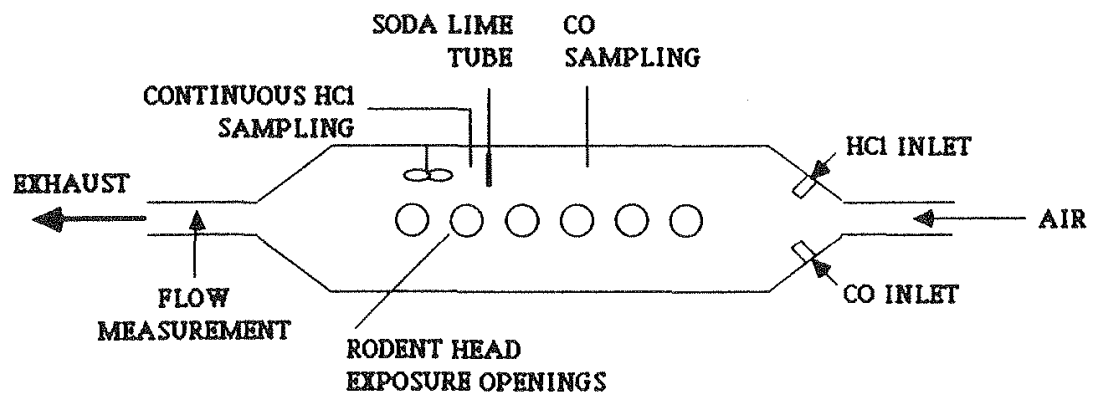

Figure 1. Schematic of flow-through exposure apparatus

Exposure Protocol. Each animal exposure test involved the exposure of six, young adult, male Sprague-Dawley rats positioned in tubular restrainers to provide for head-oniy exposure. Following insertion of the tubed animals into position through the wall of the chamber, the animal isolation system was closed and breathing air provided during the establishment of the desired test atmosphere. Thirty-minute exposures were initiated upon opening of the isolation system and termination of supplemental breathing air to the animals. The end point recorded was lethality. Surviving animals were observed until either postexposure death or 14 days. Animals surviving 14 days were subsequentiy sacrificed. Values for each $L C_{50}$, with 95-percent confidence limits, were calculated from five to seven points of data using a standard probit program.

Generation of Test Atmospheres

Pure Gas Atmospheres. "Pure gas" atmospheres were generated by the metering of the appropriate gases from cylinder sources into the exposure chamber, with continuous analytical monitoring of concentrations. Supplemental $\mathrm{O}_{2}$ was provided as necessary to maintain the $\mathrm{O}_{2}$ concentration at $20.5 \pm 1.0 \%$.

Sources were:

Carbon Monoxide (99.9\%): Scientific Gas Products Hydrogen Chloride $(99.5 \%)$ : Scientific Gas Products

Polyvinyl Chloride (PVC) Fire Effluent Atmospheres. A continuous combustion apparatus, developed at SWRI, was used for the studies reported. Shown in Figure 2, it consists of a quartz tube $1 \mathrm{~m} 7 \mathrm{ong}$ and $7.6 \mathrm{~cm}$ in diameter, with two radiant heating devices positioned exterior to the tube. One of several stainiess steel combustion boats (ranging from 50 to $110 \mathrm{~cm}$ in 1ength), containing a weighed quantity of PVC, was pulled at a constant rate of travel inside the tube past 
the radiant heater. The heat flux, sample weight and rate of travel of the combustion boat were predetermined to achieve the desired concentration of $\mathrm{HCl}$ in the fire effluent.

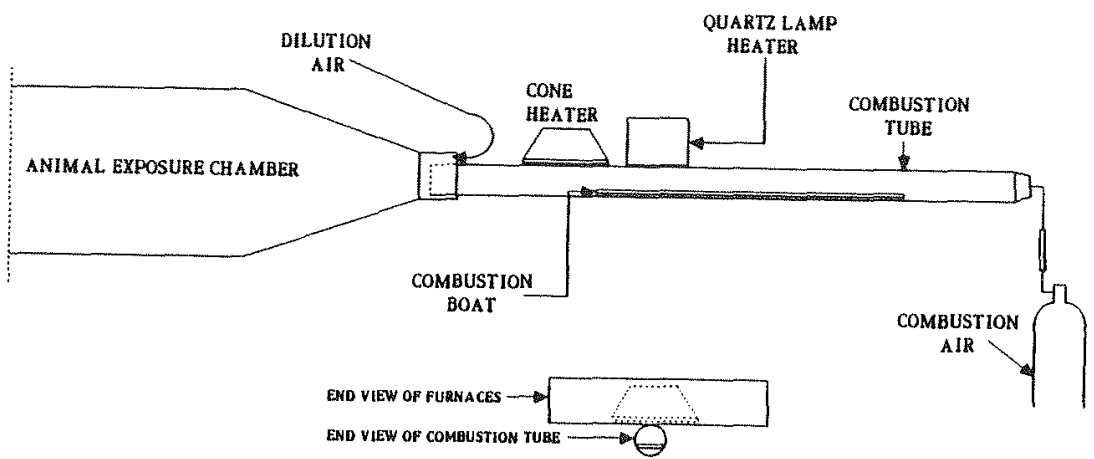

Figure 2. Continuous combustion apparatus

A constant flow of dry air $(20 \mathrm{~L} / \mathrm{min})$ was metered into the combustion tube counter-current to flame propagation, with additional room air (from $30 \mathrm{~L} / \mathrm{min}$ to approximately $200 \mathrm{~L} / \mathrm{min}$ ) being drawn into the system by an exhaust blower. The total flow of air through the apparatus was measured either by an orifice meter in the exhaust line or by calculation based on dilution of a carefully metered pure gas prior to the combustion experiments.

Different radiant heat furnaces were used for $f l a m i n g$ and for nonflaming conditions. Nonflaming combustion was conducted at $3 \mathrm{~W} / \mathrm{cm}^{2}$, using a cone heater (the same as used in the NBS cone calorimeter). However, the cone heater was unable to produce the higher fluxes $\left(6 \mathrm{~W} / \mathrm{cm}^{2}\right)$ necessary for $\mathrm{fl}$ aming PVC experiments. Therefore, a tungsten-quartz $1 \mathrm{amp}$ heating device was used for the flaming mode. A smal1 coit of resistance wire, connected to a variac and mounted inside the combustion tube, was the ignition source used to sustain flaming combustion.

Shown in Figure 3 is the relationship found between the $\mathrm{HCl}$ concentration produced and the quantity of PVC burned, expressed as $m g \cdot L^{-1}$. The latter values were estimated from the mass of PVC charged, sample travel and air flow rates.

The polyvinyl chloride (PVC) used was natural, unplasticized material in pellet form supplied by the B. F. Goodrich Chemical Company. It contained two parts lubricant and two parts stabilizer per hundred parts resin. 


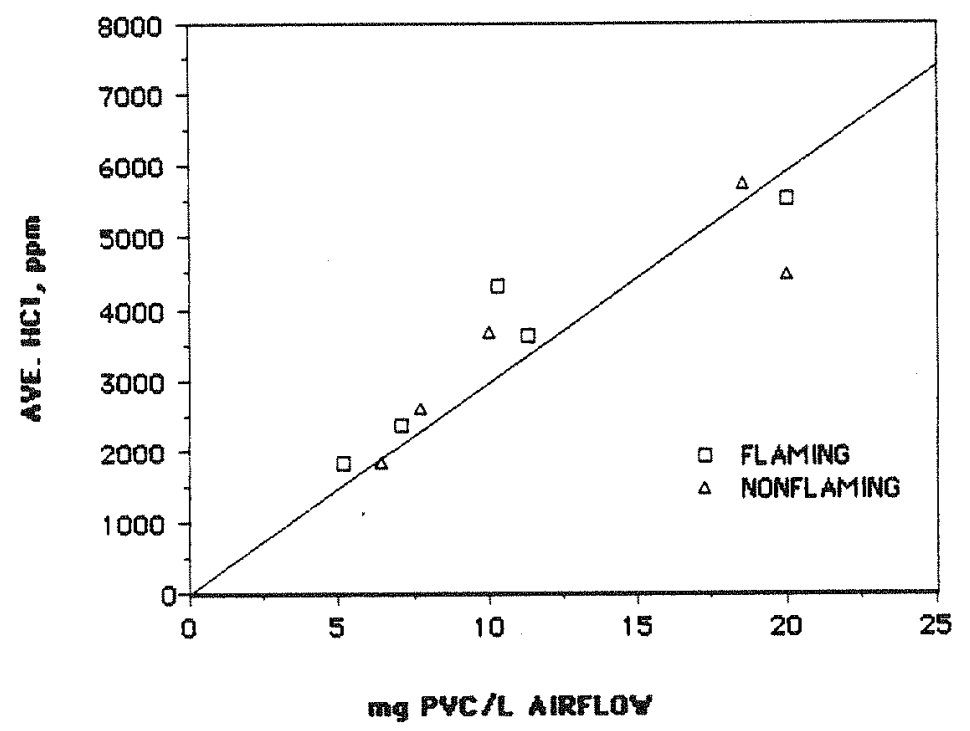

Figure 3. Plot of $\mathrm{HCl}$ concentration produced as a function of mass of PVC charged per liter of airflow

Analysis of Test Atmospheres

Asphyxiant Toxicants. Analyses of exposure atmospheres for $\mathrm{CO}, \mathrm{CO}_{2}$ and 0 , were continuously conducted using a closed loop sampling system and the following instruments:
Carbon Monoxide:
Beckman 865
Carbon Dioxide:
Beckman 865
Oxygen:
Beckman OM-11

Hydrogen Chloride. The method used for continuous monitoring of hydrogen chloride (HCl) gas, both in a "pure gas" atmosphere and in smoke, was based on that reported in a French standard test method [3], with instrumentation and procedures modified in our laboratories. Complete verification of this method, including measurement of interferences, has not been done. Therefore, for most experiments, "back-up" analyses of HCl were also performed by soda-lime tube (SLT) sampling followed by aqueous extraction and titration [4].

A schematic drawing of the continuous $\mathrm{HCl}$ method is illustrated in Figure 4. A sample of an atmosphere containing HCl is drawn continuously by a pump into a gas-solution impinger containing $0.1 \mathrm{~N} \mathrm{HNO}_{3}$ aqueous solution. A silver/silver chloride electrode (or electrode pair) and a pipette for introduction of silver nitrate $\left(\mathrm{AgNO}_{3}\right)$ titrant are positioned in the cell. The basic principle is to maintain a predetermined electrical potential (emf) in the test solution by automatically metering in $\mathrm{AgNO}_{3}$ to react with chloride ion. The rate of addition of titrant is directly proportional to the concentration of $\mathrm{HCl}$ in the sample gas stream. 


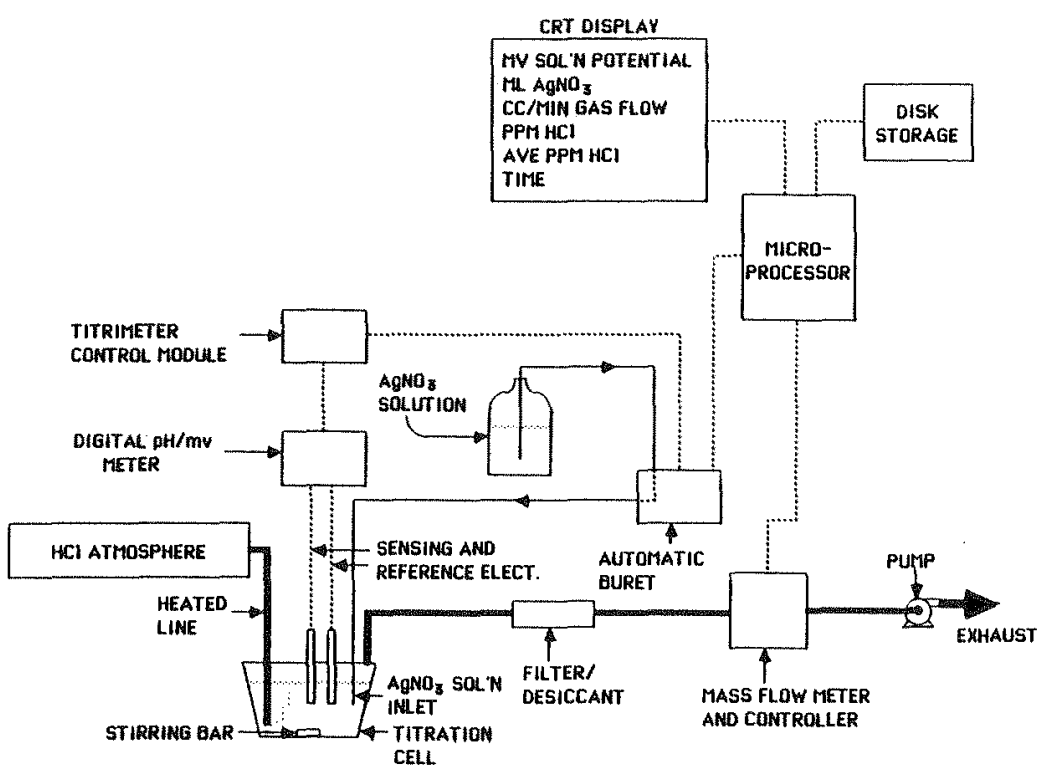

Figure 4. Continuous analysis of $\mathrm{HCl}$

In operation, any increase in $\mathrm{HCl}$ is detected as a change in the emf of the solution. This value (mv) is monitored by a digital $\mathrm{pH} / \mathrm{mv}$ meter connected to a "stat titrator" control module, which controls the dispensing of silver nitrate titrant solution through an automatic buret. When the emf of the solution deviates from the set point due to addition of chloride, the buret dispenses $\mathrm{AgNO}_{3}$ in order to return the emf to the set point. This process continues as needed to maintain the solution at the set point, which is near the equivalence point of a silver-chloride titration.

The higher the concentration of $\mathrm{HCl}$ in the test atmosphere (or the higher the gas flow rate), the faster the silver nitrate is run into the titration cell. The output of the automatic burette (mL of titrant) is 7 inked directly to an Apple IIe microcomputer for computation of $\mathrm{HCl}$ concentration. A mass flowmeter is used to monitor (and control) the gas flow, its output also going to the computer. Calculations are performed every 10 seconds in order to time-average the quantity of $\mathrm{AgNO}_{3}$ being used. Due to fluctuations in the quantity of HCl introduced into the impinger during any given 10-second increment, an additional time average is performed over three successive readings. This final averaging "smoothes out" the curve of HCT vs time. The increment of time for each calculation and the interval for determining the "average" $\mathrm{HCT}$ are both under the controT of the operator. The following data are displayed on the computer monitor every 10 seconds (or any other increment selected):

1. emf of the solution (mV);

2. Total volume of $\mathrm{AgNO}_{3}$ consumed $(\mathrm{mL})$;

3. Sample gas flow rate $(\mathrm{cc} / \mathrm{min})$; 
4. Concentration of $\mathrm{HCl}(\mathrm{ppm})$;

5. "Average" $\mathrm{HC} T$ concentration (ppm) over the selected

time interva1; and

6. Current run time (minutes and seconds).

Immediately following each experimental run, a plot of $\mathrm{HCl}$ concentration vs. time may be constructed from the stored data.

\section{RESULTS}

A total of nine LC 5 (30-minute exposure plus 14-day observation) values were determined. Data obtained are summarized in Tables 1 and 2.

Table 1. Carbon monoxide $L C_{50}$ values* (30-minute exposure +14 days)

\begin{tabular}{lcc}
\hline Atmosphere & $\mathrm{LC}_{50}(\mathrm{ppm})$ & $\begin{array}{c}95 \% \text { Confidence } \\
\text { Limits (ppm) }\end{array}$ \\
\hline CO & 6400 & $5400-7600$ \\
CO $(600 \mathrm{ppm} \mathrm{HCl)}$ & 5700 & $4800-7100$ \\
CO $(1000 \mathrm{ppm} \mathrm{HCl})$ & 5300 & $4300-6500$ \\
CO $(1000 \mathrm{ppm} \mathrm{HCl/PVC} \mathrm{smoke,} \mathrm{nonflaming)}$ & 7100 & $6300-8000$ \\
\hline
\end{tabular}

*Values are rounded to the nearest $100 \mathrm{ppm}$

Table 2. Hydrogen chioride $L_{50}$ values* (30-minute exposure +14 days)

\begin{tabular}{|c|c|c|}
\hline Atmosphere & $L_{50}(p p m)$ & $\begin{array}{l}95 \% \text { Confidence } \\
\text { Limits (ppm) }\end{array}$ \\
\hline $\mathrm{HCl}$ & 3800 & $3100-4800$ \\
\hline $\mathrm{HCl}(3000 \mathrm{ppm} \mathrm{Ce})$ & 2100 & $1500-3000$ \\
\hline HC1 (4150 ppm Co) & 1900 & $1600-2300$ \\
\hline HCl / PVC (NonfTaming-- no Co) & 2900 & $2200-3700$ \\
\hline $\mathrm{HCl} / \mathrm{PVC}$ (Flaming--avg. CO Ca, $700 \mathrm{ppm}$ ) & 2100 & $1600-2500$ \\
\hline
\end{tabular}

*values are rounded to the nearest $100 \mathrm{ppm}$

\section{DISCUSSION}

Hydrogen chloride, when present at high concentrations, is thought to penetrate into the lower respiratory tract of a subject, exerting its lethal toxic effect as a pulmonary irritant [5]. PuTmonary edema and subsequent death often follow exposure to $\mathrm{HCl}$ at high concentrations. Postexposure lethality results from exposure doses much lower than those required for either incapacitation or within-exposure lethality [6].

Concentration-response relationships for postexposure lethality of rats exposed to $\mathrm{HC}$ h have been studied over a range of exposure times from 5 minutes to 60 minutes [2]. Exposure doses (LCt ${ }_{50}^{\prime} s$ ) ranged from about $80,000 \mathrm{ppm}-\mathrm{min}$ to about $170,000 \mathrm{ppm}-\mathrm{min}$, respectively. Higher exposure doses can be tolerated if the $\mathrm{HCl}$ concentration is relatively low. Conversely, progressively higher concentrations of 
$\mathrm{HCl}$ result in tolerance to decreasing exposure doses. The 30 -minute $\mathrm{LC}_{50}$ (postexposure lethality) for $\mathrm{HCl}$ was determined to be about $3700 \mathrm{ppm}$ within a static system [2] and about $3800 \mathrm{ppm}$ for a flowthrough system. Considering the 95-percent confidence limits, the difference between these two values is not significant.

Very limited experience with baboons has indicated that $150,000 \mathrm{ppm}$-min (5- to 15-minute exposures) is probabiy on the threshold of postexposure lethality [2]. A7though there has been no experience with human exposures under controlled conditions, somewhat conservative estimates based on the nonhuman primate experience wouTd indicate that perhaps $100,000 \mathrm{ppm}-\mathrm{min}$ would likely result in very severe complications and even death. Exposure doses as low as about $20,000 \mathrm{ppm}-\mathrm{min}$ may be quite dangerous, however.

The 30-minute (pTus 14-day observation) $L C_{50}$ of $\mathrm{HCl}$ as contained in smoke from the nonflaming decomposition of PVC llittle or no co present) was found to be $2900 \mathrm{ppm}$. Although somewhat lower than the value of $3800 \mathrm{ppm}$ for $\mathrm{HCT}$, itself, it would be most reasonable to conclude that the postexposure lethal toxicity $\left(L C_{50}\right)$ of nonflaming PVC smoke can largely be accounted for by the HCl content. Further support for this statement can be obtained from the data plotted in Figure 3, in which an $\mathrm{HCl}$ concentration of $2900 \mathrm{ppm}$ corresponds to a PVC concentration (mass charged) of about $10 \mathrm{mg} \cdot \mathrm{L}^{-1}$. A though this value is somewhat lower than that reported from the NBS cup furnace test [1], a greater observed toxicity of PVC smoke would be expected from the combustion method used in this study due to the absence of any $\mathrm{HCl}$ generation delay time and also the absence of $\mathrm{HCl}$ decay.

The mechanism of action of $\mathrm{HCl}$ is so very different physiologically from that of $\mathrm{CO}$, that it would be anticipated that these two toxicants should be considered separately in predicting hazardous exposure conditions through the use of the Fractional Effective Dose model [7]. Fractional doses would not be expected to be additive, as in the case of $\mathrm{CO}$ and $\mathrm{HCN}$. However, the $\mathrm{LC}_{50}$ data on mixtures of $\mathrm{CO}$ and $\mathrm{HCT}$ tempt one to consider additivity on an empirical basis. In Table 3 are shown data for some 7 imited mixtures of $\mathrm{CO}$ and $\mathrm{HCl}$ in which the summation of fractional lethal doses approximates unity for 50-percent Tethality with 30 -minute exposures.

Table 3. Sumation of fractional effective (lethal) doses for 30-minute exposure of rats to mixtures of $\mathrm{CO}$ and $\mathrm{HCl}$

\begin{tabular}{|c|c|c|c|c|}
\hline \multicolumn{2}{|r|}{$\mathrm{CO}$} & \multicolumn{2}{|c|}{$\mathrm{HCl}$} & \multirow[b]{2}{*}{ FED } \\
\hline & Fractional Lethal & & ional Lethal & \\
\hline $\mathrm{ppm}$ & Dose & $\mathrm{ppm}$ & Dose & ( $50 \%$ Lethality) \\
\hline 6400 & 1.0 & $-m$ & - & 1.0 \\
\hline 5700 & 0.89 & 600 & 0.16 & 1.05 \\
\hline 5300 & 0.83 & 1000 & 0.26 & 1.09 \\
\hline 4150 & 0.65 & 1900 & 0.50 & 1.15 \\
\hline 3000 & 0.49 & 2100 & 0.55 & 1.04 \\
\hline-- & -- & 3800 & 1.0 & 1.0 \\
\hline
\end{tabular}

A comparable treatment of data using PVC as the source of $\mathrm{HCl}$ is shown in Table 4. It would first appear that the toxicity of smoke from nonflaming $P V C$ is somewhat greater than expected from summation of $\mathrm{HCl}$ 
FED's. However, in view of the 95-percent confidence limits, the significance is questionable. Summation of $C O$ and HCl FED's for smoke from the flaming combustion of PVC does not adequately account for its greater than expected toxicity, a difference which is suggested to be significant. The full explanation may be quite complex, since the gas/aerosol/particulate nature of the real smoke may resuit in a different pattern of respiratory penetration than for $\mathrm{HCl}$, alone. For example, particulate deposition in the upper respiratory tract may obstruct breathing of rodents and further stress an already compromised oxygen transport system. In the case of smoke from the nonflaming combustion of PVC to which has been added sufficient CO such that the $C O$ is the major toxicant, the summation of FED's indicates the mixture to be less toxic than expected. This may be due to the $\mathrm{HCl}$ being present in such a low concentration that only sensory irritation is exhibited. This would decrease the apparent toxicity of co through decreased respiration and slower loading of the co.

Tab1e 4. Summation of fractional effective (letha1) doses for 30-minute exposure of rats to mixtures of $\mathrm{CO}$ and $\mathrm{HCl}$ as produced from $\mathrm{PUC}$

\begin{tabular}{|c|c|c|c|c|c|c|}
\hline \multicolumn{2}{|r|}{$\mathrm{CO}$} & \multicolumn{3}{|c|}{$\mathrm{HCl}$} & \multirow{3}{*}{\multicolumn{2}{|c|}{$\begin{array}{c}\text { FED } \\
\text { (50\% Letha } 1 \text { ity) }\end{array}$}} \\
\hline & Fractional Lethal & \multirow[b]{2}{*}{$\mathrm{ppm}$} & \multicolumn{2}{|c|}{ Fractional Lethal } & & \\
\hline $\mathrm{ppm}$ & Dose & & & Dose & & \\
\hline- & - & 2900 & (nonflaming) & 0.76 & & 0.76 \\
\hline $\mathrm{ca} .700$ & $\mathrm{ca} \cdot 0.11$ & 2100 & (f1 aming) & 0.55 & & $\mathrm{ca} \cdot 0.66$ \\
\hline 7100 & 1.11 & 1000 & (nonflaming) & 0.26 & & 1.37 \\
\hline
\end{tabular}

Particularly striking, both in the case of the flaming combustion of PVC (with which up to $1680 \mathrm{ppm} \mathrm{CO}$ was produced) and in the case of HCT in the presence of $3000 \mathrm{ppm} C 0$ supplied from a cylinder source, was the incidence of postexposure deaths the same day as the exposure, usually within an hour. This is rare, except at high concentrations, for $\mathrm{HCT}$, alone. Data showing the incidence of these early postexposure deaths are shown in Table 5 .

Table 5. Composite lethality of rats exposed to atmospheres containing hydrogen chloride*

\begin{tabular}{|c|c|c|c|c|c|c|c|c|}
\hline \multirow[b]{2}{*}{ Atmosphere } & \multirow{2}{*}{$\begin{array}{l}\text { Animals } \\
\text { Exposed }\end{array}$} & \multicolumn{5}{|c|}{ Number of Deaths } & \multicolumn{2}{|r|}{$L C_{50}$} \\
\hline & & Exposure & Day 0 & Days $1-4$ & Days & $5-14$ & $\mathrm{HCl}$ & in $\mathrm{ppm}$ \\
\hline $\mathrm{HCl}$ & 60 & 0 & 0 & 21 & & 9 & & 3800 \\
\hline PVC Smoke-Nonflaming & 36 & 0 & 0 & 10 & & 8 & & 2900 \\
\hline PVC Smoke-Flaming & 30 & 1 & 4 & 5 & & 19 & & 2100 \\
\hline $\mathrm{HCl}+3000 \mathrm{ppm} \mathrm{CO}$ & 30 & 1 & 2 & 8 & & 17 & & 2100 \\
\hline
\end{tabular}

*At nominal approximate HCl concentrations of $1800,2600,3500,4300,5500$ and 6500 ppm

Attempts to elucidate the effect of $c 0$ on the postexposure lethality of HCl were inconclusive, but did suggest somewhat impaired ability of rats to return to homeostas is following exposure. Exposure of rats to a mixture of $5300 \mathrm{ppm} \mathrm{HCl}$ and $3000 \mathrm{ppm} \mathrm{CO}$ was characterized by a relatively rapid initial drop in blood $\mathrm{pH}$ and slower than normal postexposure unloading of $\mathrm{COHb}$. Even with these data (compared with those for co alone), it is difficult to speculate as to the cause of the in- 
cidence of same day postexposure lethality. The observations reported with rodents may pose some significance in the case of immediate postexposure complications following human exposures to mixtures of $c 0$ and $\mathrm{HCl}$ (e.g., prolonged hypoxemic conditions after rescue or escape).

In summary, it would seem that the lethal toxicity of combinations of $\mathrm{CO}$ and $\mathrm{HCl}$ can be predicted from an FED model. However, only limited success was obtained when applied to real smoke from PVC. This may be due to complications in respiratory penetration patterns involved with the complex gas/aerosol/particulate mixtures found in smoke.

\section{ACKNOWLEDGEMENT}

This work was supported under U. S. National Bureau of Standards Grant No. 60NANB6D0635. Development of the analytical and combustion methodology described was supported by the Vinyl Institute of The Society of the Plastics Industry, Incorporated.

\section{REFERENCES}

1. Levin, B. C., A. J. Fowell, M. M. Birky, M. Paabo, A. Stolte and D. Malek, "Further Development of a Test Method for the Assessment of the Acute Inhalation Toxicity of Combustion Products," NBSIR 82-2532, National Bureau of Standards, Gaithersburg, Maryland (1982).

2. Hartzel1, G. E., S. C. Packham, A. F. Grand and W. G. Switzer, "Modeling of Toxicological Effects of Fire Gases: III. Quantification of Post-Exposure Lethality of Rats from Exposure to HC1 Atmospheres," J. Fire Sciences, Vol. 3, pp. 195-207 (May/June 1985).

3. French Standard (AFNOR) FD $\times 70101$ December 1982, "Analysis of Combustion and Pyrotysis Gases - Smoke Chamber Method."

4. Grand, A. F., H. L. Kaplan, J. J. Beitel, W. G. Switzer and G. E. Hartze11, "An Evaluation of Toxic Hazards from Full-Scale Furnished Room Fire Studies," Fire Safety: Science and Engineering, ASTM STP 882, T. Z. Harmathy, Ed., American Society for Testing and MateriaTs, Philadelphia, Pennsylvania, pp. 330-353 (1985).

5. Klimisch, H. J., J. E. Doe, G. E. Hartzell, S. C. Packham, J. Pauluhn and D. A. Purser, "Bioassay Procedures for Fire Effluents: Basic Principles, Criteria and Methodology," J. Fire Sciences (In Press).

6. Kaplan, H. L., A. F. Grand, W. G. Switzer, D. S. Mitche11, W. R. Rogers and G. E. Hartzell, "Effects of Combustion Gases on Escape Performance of the Baboon and the Rat," J. Fire Sciences, Vol. 3, pp. 228-244 (July/August 1985).

7. Hartzel1, G. E., D. N. Priest and W. G. Switzer, "Modeling of Toxicological Effects of Fire Gases: II. Mathematical Modeling of Intoxication of Rats by Carbon Monoxide and Hydrogen Cyanide," J. Fire Sciences, Vol. 3, pp. 115-128 (March/ApriT 1985). 
